\title{
CHARACTERISTICS AND ASSOCIATIONS OF ULCERATIVE COLITIS IN PAKISTANI POPULATION.
}

1. MD (Gastroenterology)

Associate Professor

Gastroenterology

Continental Medical College/

Hayat Memorial Hospital, Lahore,

Pakistan.

2. MBBS, FCPS (Medicine)

Assistant Professor Medicine

Rashid Latif Medical College/

Arif Memorial Hospital, Lahore,

Pakistan.

3. FCPS (Medicine)

Associate Professor Medicine Independent Medical College/ Independent University Hospital, Faisalabad, Pakistan.

4. MBBS, FCPS (Medicine)

Assistant Professor

King Edward Medical University/

Mayo Hospital Lahore.

5. MBBS, FCPS (Medicine)

Associate Professor Medicine Independent Medical College/

Independent University Hospital,

Faisalabad, Pakistan

6. MBBS, FRCP

Professor Medicine

Allama Iqbal Medical College/

Jinnah Hospital, Lahore, Pakistan.

Correspondence Address:

Dr. Imran Anwar Khan

Continental Medical College/

Hayat Memorial Hospital, Lahore,

Pakistan.

drimrananawarkhan@gmail.com

Article received on:

07/01/2020

Accepted for publication:

13/04/2020
Imran Anwar Khan', Sadaf Yousaf', Touseef Anwar ${ }^{3}$, Muhammad Rashid Ali $^{4}$, Muhammad Sarfraz Aftab Mohsin ${ }^{6}$

ABSTRACT... Objectives: To determine the prevalence of ulcerative colitis, extent and associations of disease with age, gender, indication of the procedure and coexisting disorders in patients who underwent sigmoidoscopy at Liver Clinic, Lahore, Pakistan. Study Design: Retrospective study. Setting: Liver Clinic, Lahore. Period: February 2010 to July 2017. Material \& Methods: Group of ulcerative colitis patients was compared with group without ulcerative colitis among who underwent sigmoidoscop y from genders, age groups, indication for sigmoidoscopy, and presence of ulcerative colitis were the qualitative variables, while age of the patients was the only quantitative variable. Results: Out of total of 998 patients who underwent sigmoidoscopy, $115(11.52 \%)$ had ulcerative colitis. The mean age of ulcerative colitis patients was $37.87+14.23$ years while mean age of patients not suffering ulcerative colitis was $44.42 \pm$ 15.29 years. Among ulcerative colitis suffering cohort, $6.1 \%$ were children, $41.7 \%$ young adults, $44.3 \%$ middle aged adults and $7.8 \%$ were older adults. Out of 115 patients, $22(19.1 \%)$ had ulcerative proctitis, 25 (21.7\%) ulcerative proctosigmoiditis and in remaining 68 (59.1\%) patients had colitis throughout visualized tract. 29 (25.2\%) ulcerative colitis patients had supplementary associated disorders: 11 (37.9\%) had superimposed pseudomembranous colitis, 8 (27.6\%) had pseudopolyps formation, 7 (24.1\%) had solitary benign polyps, 2 (6.9\%) had internal hemorrhoids and 1 (3.4\%) had malignant growth as well. The ulcerative colitis was more prevalent in female gender $(p<0.01)$, younger age group $(p<0.01)$ and where bloody diarrhea was presenting complaint $(p<0.01)$. Conclusion: Ulcerative colitis is prevalent in all age groups and female gender is more affected in our population. Majority patients have disease not limited to only rectum and sigmoid colon, rather possess aggressive disease pattern associated with more risks and hazards.

Key words: $\quad$ Proctocolitis, Sigmoidoscopy, Ulcerative Colitis, Polyes.

Article Citation: Khan IA, Yousaf S, Anwar T, Ali MR, Sarfraz M, Mohsin A. Characteristics and associations of Ulcerative colitis in Pakistani population. Professional Med J 2020; 27(5):1079-1084. DOI: 10.29309/TPMJ/2020.27.05.4446

\section{INTRODUCTION}

Ulcerative colitis is a long-lasting inflammation of the mucosa of rectum and colon. ${ }^{1}$ It is an idiopathic disease that has relapsing and remitting course. ${ }^{2}$ In Asia, the prevalence of ulcerative colitis is variable and ranges from 5.3 to 63.6 per 100000 population..$^{3,4}$ The disease is relatively less prevalent among the children and most cases are being diagnosed at age between 30 to 40 years. ${ }^{5}$ The gender wide distribution of the ulcerative colitis varies in different countries. ${ }^{6,7}$ The presentation of the disease is usually bloody diarrhea. ${ }^{8}$ Truelove and Witt's criteria;' explains the clinical severity of the disease while Montreal classification ${ }^{10}$, elaborates the endoscopic extant of the disease. Based on the endoscopic extent, ulcerative colitis can be classified as proctitis, proctosigmoiditis, left sided colitis and extensive colitis. The differentiation between the last two categories is the splenic flexure. More than 6 bloody stools per day with fever, anemia, tachycardia and ESR more than $\mathbf{3 0}$ states severe ulcerative colitis. ${ }^{11}$

The extent of ulcerative colitis controls the prognosis as well as the clinical course of the disease. Therefore, extensive colitis likely needs more rigorous therapies or even colectomy ${ }^{12,13}$ Similarly, the patients with extensive colitis are at higher risk for development of colorectal cancer; whereas patients with ulcerative proctitis has no such risk. ${ }^{14}$ 
The objective of this study was to determine the determine the prevalence of ulcerative colitis, extent and associations of disease with age, gender, indication of the procedure and coexisting disorders in patients who underwent sigmoidoscopy at Liver Clinic, Lahore, Pakistan.

\section{MATERIAL \& METHODS}

This retrospective analysis was carried out on patients who underwent sigmoidoscopy from February 2010 to July 2017 at Liver clinic, 250 Shadman Lahore. The patients who were diagnosed as suffering ulcerative colitis and who had no ulcerative colitis finding on sigmoidoscopy were categorized into two cohorts. Based on age, the patients were distributed into four groups: child had age less than 19 years, young adults 19-35 years, middle age adults $36-55$ years and older adults had age $>55$ years. ${ }^{15}$

Based on the sigmoidoscopic findings, extent of the ulcerative colitis was grouped as follow: The disease restricted to rectum was labelled as ulcerative proctitis, while disease including both rectum and sigmoid colon was called as ulcerative proctosigmoiditis. The involvement throughout visualized gut tract till splenic flexure was a third category, which was further advised complete colonoscopy to differentiate left-sided colitis from extensive colitis. All the additional findings like superimposed, pseudopolyps formation, malignant growth, and pseudomembranous colitis etc. were also noted. The symptoms for which the sigmoidoscopy was performed were grouped into two categories: one with bloody diarrhea while second one without bloody diarrhea.

The age groups, genders, indication for sigmoidoscopy, and presence of ulcerative colitis were the qualitative variables, while age of the patients was the only quantitative variable. Statistical Package for Social Science (SPSS), version 25 was used. Means with standard deviationswerecomputed of quantitativevariables, and frequencies-percentages for qualitative variables. Chi-square test for independence and Independent sample $\mathrm{T}$ test were used for qualitative and quantitative variables respectively to determine their significant association with presence of ulcerative colitis. The $p$ values were taken statistically significant if $<0.05$. Moreover, odds ratio along with their $95 \%$ confidence interval (Cl) were also calculated for each association.

\section{RESULTS}

Out of total of 998 patients who had sigmoidoscopy, 115 (11.52\%) were diagnosed as suffering ulcerative colitis. The mean age of these ulcerative colitis patients was $37.87+$ 14.23 years. The distribution of ulcerative colitis in different age groups was as follow: $6.1 \%$ were children, $41.7 \%$ young adults, $44.3 \%$ middle aged adults and $7.8 \%$ were older adults among who were suffering ulcerative colitis. (Figure-1). Out of 115 patients, 22 (19.1\%) patients had ulcerative proctitis, $25(21.7 \%)$ ulcerative proctosigmoiditis and in remaining 68 (59.1\%) patients ulcerative colitis was seen throughout visualized tract from rectum till splenic flexure (Table-I). This last group included 2 categories i.e. left sided colitis as well as extensive colitis. For differentiation, these patients were asked for complete colonoscopic examination.

29 (25.2\%) patients with ulcerative colitis had supplementary associated disorders. 11 (37.9\%) ulcerative colitis patients had superimposed pseudomembranous colitis, $8(27.6 \%)$ colitis patients had pseudopolyps formation, 7 (24.1\%) had solitary benign polyps, 2 (6.9\%) had internal hemorrhoids and 1 (3.4\%) patient had malignant growth as well. (Table-II)

The ulcerative colitis was more prevalent in female gender $(p<0.01)$, where among 115 ulcerative colitis suffering patients, $40.9 \%(n=47)$ were female while among 1083 patients not suffering Ulcerative colitis, only $28 \%$ were female while $72 \%$ were male. Similarly, ulcerative colitis suffering patients were younger than who not having ulcerative colitis $(p<0.01)$. The mean age of ulcerative colitis patient was $37.87+14.34$ years while mean age of patients not suffering ulcerative colitis was $44.42+15.29$ years. Among patients diagnosed having ulcerative colitis, $87.8 \%$ underwent sigmoidoscopic 
procedure for the indication of bloody diarrhea while among patients with diagnosed as having no ulcerative colitis, $40.7 \%$ presented with bloody diarrhea.The association of bloody diarrhea as indication of sigmoidoscopy with diagnosis of ulcerative colitis was also statistically significant $(p<0.01)$. (Table-III) Hence, younger age, female gender with bloody diarrhea as chief symptom for sigmoidoscopic procedure predicts the likely diagnosis would be ulcerative colitis.

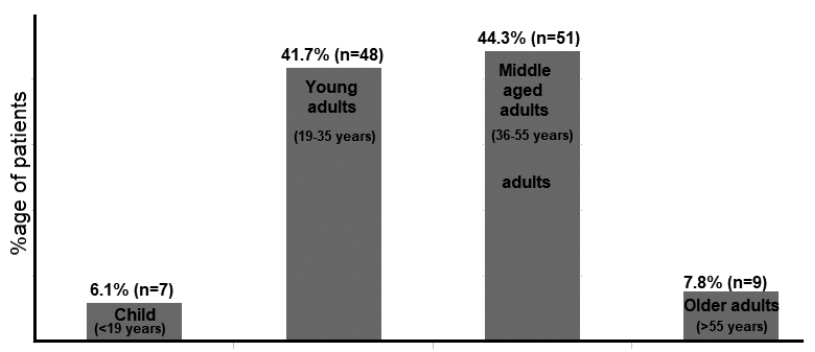

Picture 1: Distribution of Ulcerative colitis in different age groups $(n=115 / 998)$

Figure-1. Distribution of Ulcerative colitis in different age groups $(n=115 / 998)$

Frequency (Percent)

Ulcerative proctitis

Ulcerative proctosigmoiditis

Ulcerative colitis, involving rectum till splenic flexure

Table-I. Sigmoidoscopic extent classification of ulcerative colitis $(n=115 / 998)$.

\section{Associated disorders with ulcerative colitis}

Ulcerative colitis with superimposed Pseudomembranous colitis

Ulcerative colitis with Pseudopolyps formation

Ulcerative colitis with Solitary benign polyps

Ulcerative colitis with Internal hemorrhoids

Ulcerative colitis with malignant growth
Frequency (Percent)

$11(37.9 \%)$

$8(27.6 \%)$

$7(24.1 \%)$

2 (6.9\%\%)

$1(3.4 \%)$

Table-II. Disorders associated with Ulcerative colitis $(n=29 / 115)$.

\begin{tabular}{|c|c|c|c|c|c|}
\hline \multirow{2}{*}{ Parameters /Categories ${ }^{*}$} & \multicolumn{2}{|c|}{ Ulcerative colitis } & \multirow[b]{2}{*}{ Total } & \multirow{2}{*}{ p-value } & \multirow{2}{*}{$\begin{array}{l}\text { Odd ratio with } 95 \% \\
\text { Confidence interval }\end{array}$} \\
\hline & Yes & No & & & \\
\hline $\begin{array}{l}\text { Gender } \\
\text { Male } \\
\text { Female }\end{array}$ & $\begin{array}{l}68(59.1 \%) \\
47(40.9 \%)\end{array}$ & $\begin{array}{l}636(72 \%) \\
247(28 \%)\end{array}$ & $\begin{array}{l}704 \\
294\end{array}$ & $<0.01$ & $1.78(1.19-2.65)$ \\
\hline Mean Age (Years) & $\begin{array}{c}37.87 \pm \\
14.34\end{array}$ & $44.42 \pm 15.29$ & 998 & $<0.01$ & $1.51(-9.505--3.60)$ \\
\hline $\begin{array}{l}\text { Indication of sigmoidoscopy } \\
\text { Bloody diarrhea } \\
\text { Others }\end{array}$ & $\begin{array}{c}101(87.8 \%) \\
14(12.2 \%)\end{array}$ & $\begin{array}{l}359(40.7 \%) \\
524(59.3 \%)\end{array}$ & $\begin{array}{l}460 \\
538\end{array}$ & $<0.01$ & $10.53(5.93-18.71)$ \\
\hline
\end{tabular}




\section{DISCUSSION}

Ulcerative colitis and crohn's disease both are included in inflammatory bowel disease, where first one is relatively more common in Asia. ${ }^{16}$ According to Siew C. Ng work done in 2016, in Asia, the incidence of ulcerative colitis is 1 per 100,000 people while that of crohn's disease is about 0.5 per 100,000 persons. ${ }^{17}$ In the study from Ireland ${ }^{18}$, the rate of ulcerative colitis among patients who had sigmoidoscopic examination was only $2 \%$. In our findings, 115 patients among 998 i.e. $11.52 \%$ had ulcerative colitis among all those who underwent sigmoidoscopy. International data suggests that ulcerative colitis is less prevalent in children and the age at the time of diagnosis of the disease is usually between 30 and 40 years in majority ulcerative colitis patients. ${ }^{5}$ The recent data is directing towards increasing incidence of paediatric inflammatory bowel disease. ${ }^{19,20}$ Our study disclosed that distribution of ulcerative colitis in our population in different age groups has a decremental pattern with more prevalence in children and least in older adults. This a appoint to be worried because higher frequency of ulcerative colitis patients at endoscopy suite (2\% vs $11.52 \%)$ and more prevalence at child age group favors high disease burden in our population. A large sample size Asian study on extent of ulcerative colitis ${ }^{21}$ concluded that the commonest subcategory was proctitis (proctitis: $37 \%$; distal colitis: $32 \%$; extensive colitis: $31 \%)$. However, in our studied population, it was found in reverse i.e. (proctitis: 19.1\%: proctosigmoiditis: $21.7 \%$; Involvement till visualizing splenic flexure: $59.1 \%$ ). This finding points towards more extensive engrossment by disease in our population. Furthers studies are required to elaborate this hypothesis.

American study of 35404 patients of ulcerative colitis testified and concluded that ulcerative colitis is more prevalent among female gender ${ }^{7}$, while previously in Asia male predominance was observed. ${ }^{6}$ However, our study showed significant proportion of females $(p<0.01)$ suffering ulcerative colitis. In another study from Pakistan ${ }^{22}$, the predominant presenting symptom among ulcerative colitis patients was mucous diarrhea in $90.7 \%(n=49)$, while in our study, the chief presenting symptom was bloody diarrhea in studied population of ulcerative colitis $(87.8 \%$; $\mathrm{n}=101)$.

The prevalence of pseudomembranous colitis in our study (9.56\%, 11 out of 115 patients) was more than double in comparison to available US data (3.7\%). ${ }^{23}$ This stressto improve hygienic conditions and avoidance of undue antibiotics in ulcerative colitis patients in our people. However larger studies are required to further validate these findings.

\section{CONCLUSION}

Ulcerative colitis is prevalent in all age groups, being female gender more affected in our population. Majority patients have disease not limited to only rectum and sigmoid colon, rather possess aggressive disease pattern associated with more risks and hazards. Ulcerative colitis usually presents with bloody diarrhea in our people. There are multiple coexisting disorders, where higher prevalence of pseudomembranous colitis demands avoidance of undue antibiotics and better hygiene in our patients bearing ulcerative colitis.

Copyright $(13$ Apr, 2020.

\section{REFERENCES}

1. Tripathi K, Feuerstein JD. New developments in ulcerative colitis: Latest evidence on management, treatment, and maintenance. Drugs Context. 2019; 8:212572.

2. Keshteli $\mathrm{AH}$, Madsen $\mathrm{KL}$, Dieleman LA. Diet in the pathogenesis and management of ulcerative colitis; A Review of Randomized Controlled Dietary Interventions. Nutrients. 2019; 11(7):1498.

3. Niriella MA, De Silva AP, Dayaratne AH, Ariyasinghe $\mathrm{MH}$, Navarathne MM, Peiris RS, Samarasekara DN, Satharasinghe RL, Rajindrajith S, Dassanayake AS, et al. Prevalence of inflammatory bowel disease in two districts of Sri Lanka: A hospital based survey. BMC Gastroenterol 2010; 10:32.

4. Asakura K, Nishiwaki Y, Inoue N, Hibi T, Watanabe M, Takebayashi T. Prevalence of ulcerative colitis and Crohn's disease in Japan. J Gastroenterol. 2009; 44:659-665. 
5. Cosnes J, Gower-Rousseau C, Seksik P, Cortot A. Epidemiology and natural history of inflammatory bowel diseases. Gastroenterology. 2011; 140:1785-1794.

6. Prideaux L, Kamm MA, De Cruz PP, Chan FK, Ng SC. Inflammatory bowel disease in Asia: A systematic review. J Gastroenterol Hepatol. 2012; 27:1266-1280.

7. Betteridge JD, Armbruster SP, Maydonovitch C, Veerappan GR. Inflammatory bowel disease prevalence by age, gender, race, and geographic location in the U.S. military health care population. Inflamm Bowel Dis. 2013; 19:1421-1427.

8. Osterman MT, Lichtenstein GR. Ulcerative colitis. In: Feldman M, Friedman L, Brandt L, editors. Sleisenger and Fortran's Gastrointestinal and Liver disease. 10th Ed. Philadelphia: Elsevier; 2016: 2316-2336.

9. Truelove SC, Witts LJ. Cortisone in ulcerative colitis; Preliminary report on a therapeutic trial. Br Med J. 1954; 2: 375-378.

10. Satsangi J, Silverberg MS, Vermeire S, Colombel JF. The Montreal classification of inflammatory bowel disease: Controversies, consensus, and implications. Gut. 2006; 55: 749-753.

11. Luo CX, Wen $Z \mathrm{H}$, Zhen $\mathrm{Y}$, et al. Chinese research into severe ulcerative colitis has increased in quantity and complexity. World J Clin Cases. 2018; 6(3):35-43. doi:10.12998/wjcc.v6.i3.35.

12. Alkim C, Alkim H, Dağli U, Parlak E, Ulker A, Sahın B. Extension of ulcerative colitis. Turk J Gastroenterol. $2011 ; 22$ : 382-387.

13. Kiss LS, Lakatos PL. Natural history of ulcerative colitis: Current knowledge. Curr Drug Targets. 2011; 12:1390-1395.

14. Jess T, Rungoe C, Peyrin-Biroulet L. Risk of colorectal cancer in patients with ulcerative colitis: A meta-analysis of population-based cohort studies. Clin Gastroenterol Hepatol. 2012; 10:639-645.
15. Petry NM A comparison of young, middle-aged, and older adult treatment-seeking pathological gamblers. Gerontologist 2002; 42(1): 92-9.

16. Ng SC. Inflammatory bowel disease in Asia. Gastroenterol Hepatol (N Y). 2013; 9(1):28-30.

17. $\mathrm{Ng} \mathrm{SC}$. Emerging trends of inflammatory bowel disease in Asia. Gastroenterol Hepatol (N Y). 2016; 12(3):193-196.

18. Ahmed A, Sadadcharam G, Lynch N, Myers E and Andrews $E$. Diagnostic yield of flexible sigmoidoscopy in symptomatic population: An insight to rapid access sigmoidoscopy clinic. Surg Res Open J 2014; 1(1): 10-16.

19. Lopez RN, Appleton L, Gearry RB, and Day AS. Rising incidence of paediatric inflammatory bowel disease in Canterbury, New Zealand, 1996-2015. J Pediatr Gastroenterol Nutr 2017; 1(1); 1-10.

20. Benchimol El, Fortinsky KJ, Gozdyra P, Heuvel MV, Limbergen JV, and Griffiths AM. Epidemiology of pediatric inflammatory bowel disease: A systematic review of international trends. Inflamm Bowel Dis 2011; 17 (1): 423-439.

21. Ng SC, Tang W, Ching JY, Wong M, Chow CM, et al. Incidence and phenotype of inflammatory bowel disease based on results from the Asia-pacific Crohn's and colitis epidemiology study. Gastroenterology 2013; 145: 158-165.

22. Qureshi M and Abbas Z. Clinical presentation of ulcerative colitis in Pakistani adults. EJOHG 2015; 5 (2): $127-130$.

23. Nguyen GC, Kaplan, Harris ML, and Brant SR. A national survey of the prevalence and impact of Clostridium difficile infection among hospitalized inflammatory bowel disease patients. Am J Gastroenterol 2008; 103 (6): 1443-1450. 


\begin{tabular}{|c|c|c|c|}
\hline \multicolumn{4}{|c|}{ AUTHORSHIP AND CONTRIBUTION DECLARATION } \\
\hline Sr. \# & Author(s) Full Name & Contribution to the paper & Author(s) Signature \\
\hline 1 & Imran Anwar Khan & Data collection, Analysis \& & \\
\hline 2 & Sadaf Yousaf & Literature search and & \\
\hline 3 & Touseef Anwar & Planning \& write up. & \\
\hline 4 & Muhammad Rashid Ali & Write up. & Re \\
\hline 5 & Muhammad Sarfraz & Proof reading \& revision. & \\
\hline 6 & Aftab Mohsin & $\begin{array}{l}\text { Consultation, supervision \& } \\
\text { proof reading. }\end{array}$ & \\
\hline
\end{tabular}

